\title{
THERMOCHEMISTRY OF 5,10,15,20-TETRAPHENYLPORPHYRIN
}

Lev S. Kudin*, Anatoly M. Dunaev, Vladimir B. Motalov

Ivanovo State University of Chemistry and Technology, 153000, Ivanovo, Av. Sheremetevsky, 7, Ivanovo 153000, Russia

Luigi Cavallo

KAUST Catalysis Center (KCC), King Abdullah University of Science and Technology, Thuwal-23955-6900, Saudi Arabia

Yury Minenkov

Moscow Institute of Physics and Technology, Institutskiy Pereulok 9, Dolgoprudny, Moscow Region 141700, Russia

\begin{abstract}
Saturated vapor pressure of 5,10,15,20-tetraphenylporphyrin (TPP) was determined by Knudsen effusion mass spectrometry technique. The temperature dependence of the vapor pressure is described by the equation $\ln p / P a=-(23.45 \pm 0.26) \cdot 10_{3} / T+37.32 \pm 0.47$ in the temperature range $490-615 \mathrm{~K}$. The specific heat capacity measurements of TPP were performed in the temperature range $169-568 \mathrm{~K}$. Quantumchemical calculations of the structure and force field of the TPP molecule were carried out. These data were used to calculate thermodynamic functions of TPP in the solid and gas states. The enthalpy of sublimation of triclinic form of TPP was determined by the second and third laws of thermodynamics. The value $\Delta_{s} H^{\circ}(298.15 \mathrm{~K})=220 \pm 12 \mathrm{~kJ} \cdot \mathrm{mol}_{-1}$ was recommended. The reaction based Feller-Peterson-Dixon approach predicts the gas phase TPP formation enthalpy $\Delta_{f} H^{\circ}(298.15 \mathrm{~K})=$ $1004 \pm 10 \mathrm{~kJ} \cdot \mathrm{mol}-1$. A combination of the two last values results in the formation enthalpy of the TPP triclinic form $\Delta_{f} H^{\circ}(298.15 \mathrm{~K})=784 \pm 15$ $\mathrm{kJ} \cdot \mathrm{mol}_{-1}$.
\end{abstract}

Keywords: tetraphenylporphyrin, Knudsen effusion mass spectrometry, vapor pressure, enthalpy of sublimation, formation enthalpy, quantum-chemical calculations, thermodynamic functions

${ }^{*}$ Corresponding author. 


\section{INTRODUCTION}

Porphyrins are macrocycles formed by four pyrrole rings connected in the $\alpha$ positions by four methine groups. A specific function of each porphyrin is determined by the variety of their substituents and by their capacity for coordination with many metallic ions or atoms. Porphyrins play an exceptional role in the natural biochemical and biophysical processes1,2. Many important biological, photochemical, and enzymatic processes occur with their participation, including but not limited to photosynthesis, oxygen transfer, electron transfer etc. Currently, various functional materials based on porphyrins, such as photosensitizers and optical materials, information storage elements, oxygen and toxic gas sensors, molecular switches, liquid crystals, organic semiconductors, catalysts, and drugs, are widely used in chemistry, molecular electronics, pharmacology, and medicine.

Despite the widespread use of porphyrins, knowledge of their thermochemical properties is neither complete nor reliable. For instance, the sublimation enthalpy of $5,10,15,20$-tetraphenylporphin (TPP), one of the main precursors of porphyrins and their substituted derivatives, obtained by various authors, is highly contradictory. The first value of the TPP sublimation enthalpy $\Delta_{s} H^{\circ}(633 \mathrm{~K})=111 \pm 5 \mathrm{~kJ} \cdot \mathrm{mol}_{-1}$ was determined in 1970 by Bonderman et al.3 using the Knudsen effusion technique from the temperature dependence of saturated vapor pressure. About that time, Edwards et al.4 studied the gas-phase absorption spectrum of TPP and calculated the TPP enthalpy of sublimation $\Delta_{s} H^{\circ}(668 \mathrm{~K})=146.4 \mathrm{~kJ} \cdot \mathrm{mol}-1$. Much later, the saturated vapor pressure of TPP was measured by Golubchikov et al.5 using the inert gas flow method. These authors reported four different sublimation enthalpy values: $\Delta_{s} H^{\circ}(598 \mathrm{~K})=267 \pm 9 \mathrm{~kJ} \cdot \mathrm{mol}_{-1}$ and $\Delta_{s} H^{\circ}(653 \mathrm{~K})=185 \pm 10 \mathrm{~kJ} \cdot \mathrm{mol}_{-1}$ for sublimed TPP and $\Delta_{s} H^{\circ}(558 \mathrm{~K})=370 \pm 40 \cdot \mathrm{kJ} \cdot \mathrm{mol}_{-1}$ and $\Delta_{s} H^{\circ}(628 \mathrm{~K})=170 \pm 5 \mathrm{~kJ} \cdot \mathrm{mol}_{-1}$ for TPP recrystallized from benzene. In later publications6,7 the same authors have reconsidered their initial interpretation, giving the value $\Delta_{s} H^{\circ}(588 \mathrm{~K})=$ $240 \pm 7 \cdot \mathrm{kJ} \cdot \mathrm{mol}_{-1}$ for TPP in tetragonal modification obtained by vacuum sublimation, and the value $\Delta_{s} H^{\circ}(578 \mathrm{~K})=207 \pm 10 \cdot \mathrm{kJ} \cdot \mathrm{mol}-1$ for triclinic TPP, grown from benzene solution. In 2002 Torres et al.8 determined the TPP sublimation enthalpy $\Delta_{s} H^{\circ}(550$ $\mathrm{K})=171 \pm 2 \mathrm{~kJ} \mathrm{~mol}_{-1}$ by the Knudsen effusion method using a quartz crystal microbalance. In 2004 Stefanov et al.9, studying fluorescence on molecular diluted beams, determined the enthalpy of sublimation of TPP, $\Delta_{s} H^{\circ}(667 \mathrm{~K})=142 \pm 3 \mathrm{~kJ}$ mol-1. Finally, in 2007 Deachapunya et al.10 using Knudsen effusion mass spectrometry (KEMS) measured the temperature dependence of the ion current $\mathrm{C}_{44} \mathrm{H}_{30} \mathrm{~N}_{4+}$, formed by electron-impact ionization of the effusive molecular beam, and obtained the TPP sublimation enthalpy as $\Delta_{s} H^{\mathrm{o}}(642 \mathrm{~K})=160 \pm 3 \mathrm{~kJ} \cdot \mathrm{mol}_{-1}$.

Thus, the TPP sublimation enthalpies determined by different authors using different techniques are inconsistent forming a wide range of individual values from 111 to $370 \mathrm{~kJ} \cdot \mathrm{mol}_{-1}$. To rationalize the available experimental data, new measurements of saturated vapor pressure of TPP were performed by KEMS. Unlike previous studies, 
in which the processing of experimental data was carried out exclusively according to the second law of thermodynamics, the third law method was also applied in this work.

\section{EXPERIMENTAL}

\section{A. Sample}

5,10,15,20-tetraphenylporphyrin (Fig. 1) was synthesized by condensation of pyrrole with benzaldehyde according to the improved method of Semeykin et al.11. The MALDI spectrum of the synthesized sample showed that the peak with $\mathrm{m} / \mathrm{z}=$ 614 , corresponding to the molecular ion TPP, is dominant. The purity of TPP according to high performance liquid chromatographic analysis was rated no worse than $98 \%$. X-ray analysis of the obtained TPP powder (Fig. 2) shows that the crystalline system has a triclinic structure (space group P1) with the following unit cell parameters: $a=6.4309(4) \AA, b=10.4711(6) \AA, c=12.4165(8) \AA, \alpha=$ $95.865(4)^{\circ}, \beta=99.296(3)^{\circ}, \gamma=101.162(3)^{\circ}$, which agree well with the literature data12. The 1 H NMR TPP spectrum (Fig. 3) is completely consistent with the reference data 13 and does not show any related impurity compounds in measurable amounts. The electron absorption spectra of the initial sample and its residue after mass spectrometric experiment, given in Fig. 4, did not reveal any differences and corresponds to the literature data14,15. Fig. 3 and 4 point out that TPP does not decompose during evaporation in the studied temperature range.

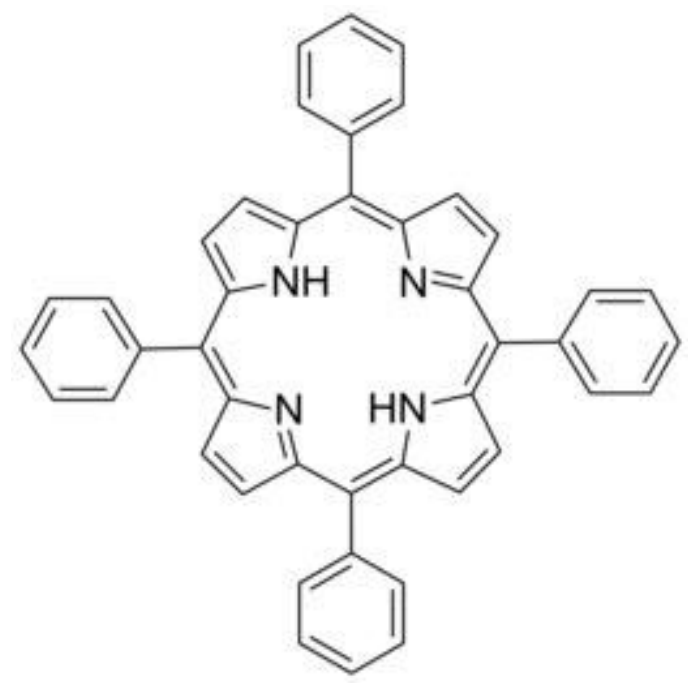

FIG. 1. 5,10,15,20-tetraphenylporphyrin (TPP) structure 


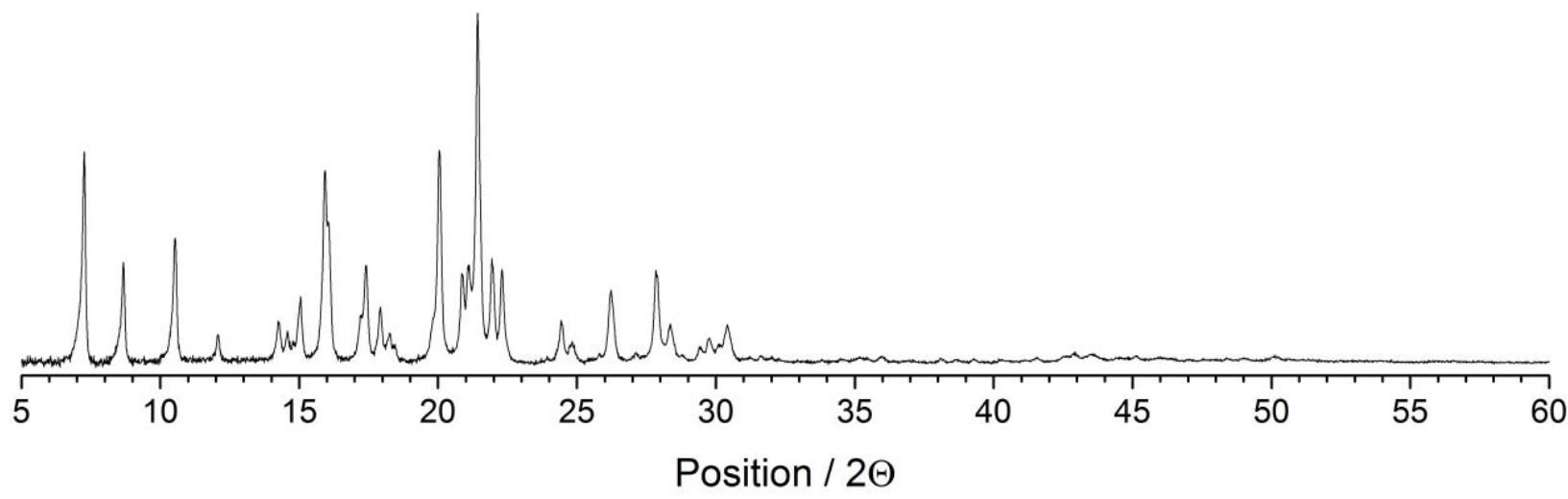

FIG. 2. X-ray diffraction pattern of TPP

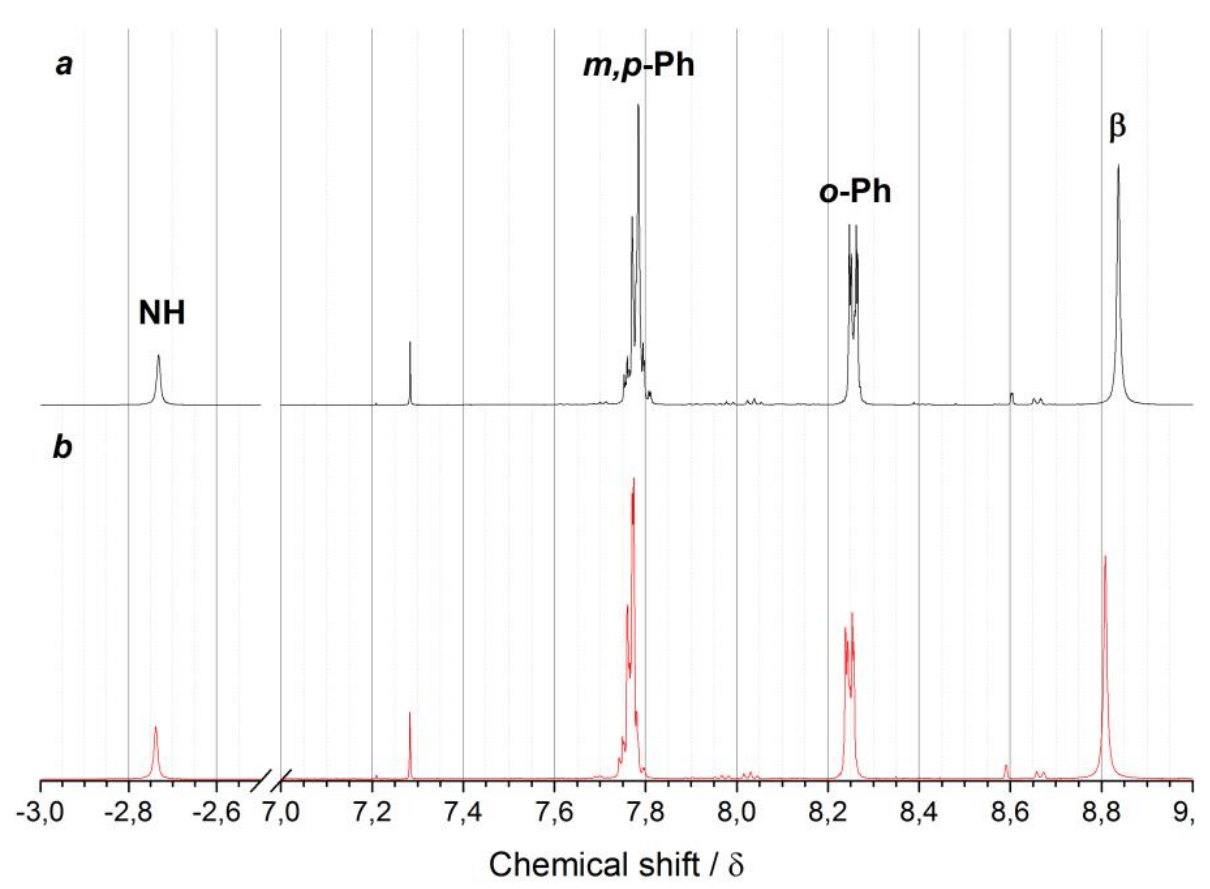

FIG. 3. $1 \mathrm{H}$ NMR spectrum of TPP: $(a)$ - initial sample, (b) - residue after mass spectrometric experiment 


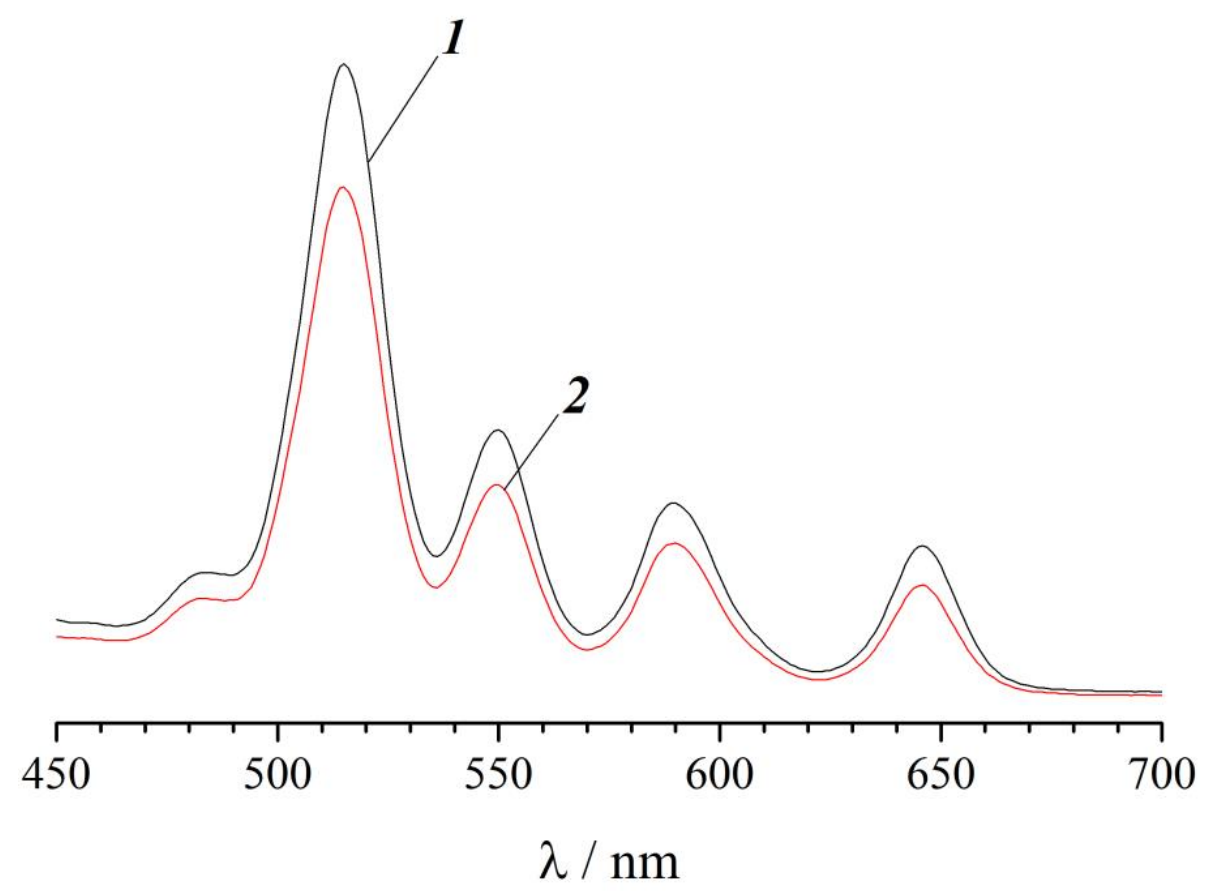

FIG. 4. Electron absorption spectrum of initial sample (1) and its residue after mass spectrometric experiment (2)

\section{B. Mass spectrometric analysis}

A magnetic sector type mass spectrometer MI201 (90, $200 \mathrm{~mm}$ curvature radius) reconstructed for high-temperature studies was used. The sample of TPP was placed into a molybdenum Knudsen cell; the diameter and the channel length of the effusion orifice were $0,7 \mathrm{~mm}$ and $0,4 \mathrm{~mm}$ correspondingly; the vaporization-to-effusion area ratio was about 400 . A resistance furnace was utilized for heating of the cell. The temperature of the cell was measured by a tungsten-rhenium thermocouple calibrated by silver to $\pm 5 \mathrm{~K}$ accuracy in the separate experiment. Molecular beam formed by effusing species reached ionization chamber and intersected electron beam of specified energy. Electrons with an energy of $40 \mathrm{eV}$ was used. The cathode current was adjusted to provide a constant emission current of $0.25 \mathrm{~mA}$ between the cathode and ionization chamber. The special software "HTMSLab" was used to control experimental parameters, collect and process the data, and export the results into the database. Detailed description of the apparatus is given elsewhere 16,17-19.

\section{Thermal analysis and heat capacity measurements}

Thermal analysis of TPP samples was carried out on a Netzsch STA 449 F3 Jupiter thermal analyzer. Measurements of mass loss and heat flow were performed 
in the temperature range $300-1023 \mathrm{~K}$ with rates of 5 and $10 \mathrm{~K}$ min-1 in an argon atmosphere. The sample was placed in a platinum pan.

The standard specific heat capacity $C_{p}$ of TPP in solid state was measured by differential scanning calorimetry (DSC) in the temperature range $169-568 \mathrm{~K}$. The DSC 204 F1 Phoenix (169 - 302 K) and DSC 404C Pegasus (328 - $568 \mathrm{~K})$ heat calorimeters (NETZSCH, Germany) with the highly sensitive sensors were used in combination with the Proteus software for Windows.20 High purity (>99.999\%) materials $\mathrm{C}_{6} \mathrm{H}_{12}$ (melting temperature $\left.280 \mathrm{~K}\right), \mathrm{Hg}(234 \mathrm{~K}), \mathrm{Pb}(327 \mathrm{~K}), \mathrm{C}_{12} \mathrm{H}_{10}(342$ $\mathrm{K}), \mathrm{In}(430 \mathrm{~K}), \mathrm{Bi}(545 \mathrm{~K}), \mathrm{C}_{6} \mathrm{H}_{5} \mathrm{COOH}(396 \mathrm{~K}), \mathrm{RbNO}_{3}(583 \mathrm{~K}), \mathrm{KClO}_{4}(683 \mathrm{~K})$, $\mathrm{Ag}_{2} \mathrm{SO}_{4}(933 \mathrm{~K})$ and $\mathrm{CsCl}(919 \mathrm{~K})$ were used to calibrate the temperature when operating the DSC experiments in the studied temperature range. Sample was heated with a rate of $10 \mathrm{~K} \mathrm{min-1}$ in argon atmosphere. The cooling system is provided with liquid nitrogen. The pre-dried sample (3-5 $\mathrm{mg}$ ) was placed in an aluminum pan and heat flow was measured by comparison with that for an empty control aluminum pallet depending on temperature. The specific heat capacity $C_{p}$ of TPP samples was determined relative to sapphire. The precision of the specific heat capacity determination was estimated to be less than $5 \%$ within the studied temperature ranges.

\section{RESULTS AND DISCUSSION}

\section{A. Thermal analysis}

The results of thermal analysis of TPP (Fig. 5) indicate the absence of any structural changes in the studied temperature range. Fig. 5 suggests a noticeable mass loss of the sample starting at a temperature of about $700 \mathrm{~K}$. The decomposition temperature was determined to be $760 \pm 30 \mathrm{~K}$. The peak on the heat flow curve corresponds to the melting temperature of $720 \pm 6 \mathrm{~K}$ and the melting enthalpy $\Delta_{m} H^{\circ}$ $=17 \pm 5 \mathrm{~kJ}$ mol- -1 .

\section{B. Mass spectra}

Scanning of masses in the range of 2-1300 Da showed that the main peaks in the electron ionization mass-spectrum in the temperature range $490-615 \mathrm{~K}$ are ions with $m / z=614$ (100) and $m / z=307$ (13). The relative intensities of ion currents at $T=$ $523 \mathrm{~K}$ are given in parentheses. It should be noted that no trace of ions with $\mathrm{m} / \mathrm{z}>$ 614 was observed in the mass spectrum. The appearance energies $(A E)$ of the registered ions, determined by the method of linear extrapolation of near-threshold portions of ionization efficiency curves (Fig. 6), are $8.2 \pm 0.5 \mathrm{eV}$ and $20.8 \pm 0.5 \mathrm{eV}$, respectively. The energy scale was calibrated using the background signal of $\mathrm{HI}_{+}$ $\left(I E(\mathrm{HI})=10.38 \mathrm{eV}_{21}\right)$. The low value of the appearance energy of the ion with $\mathrm{m} / z$ $=614$ indicates that it is the molecular ion $\mathrm{C}_{44} \mathrm{~N}_{4} \mathrm{H}_{30+}$. High appearance energy of ion with $m / z=307$ and its mass, which is two times less than that of $\mathrm{C}_{44} \mathrm{~N}_{4} \mathrm{H}_{30+}$, 
allow to attribute it to double charged molecular ion. This interpretation is confirmed by similarity of slopes of the temperature dependencies of the registered ion currents shown in Fig. 7. These dependencies were reproducible in heating and cooling cycles pointing out that TPP sublimate congruently in the studied temperature range. This conclusion is consistent with the results of thermal analysis described above.

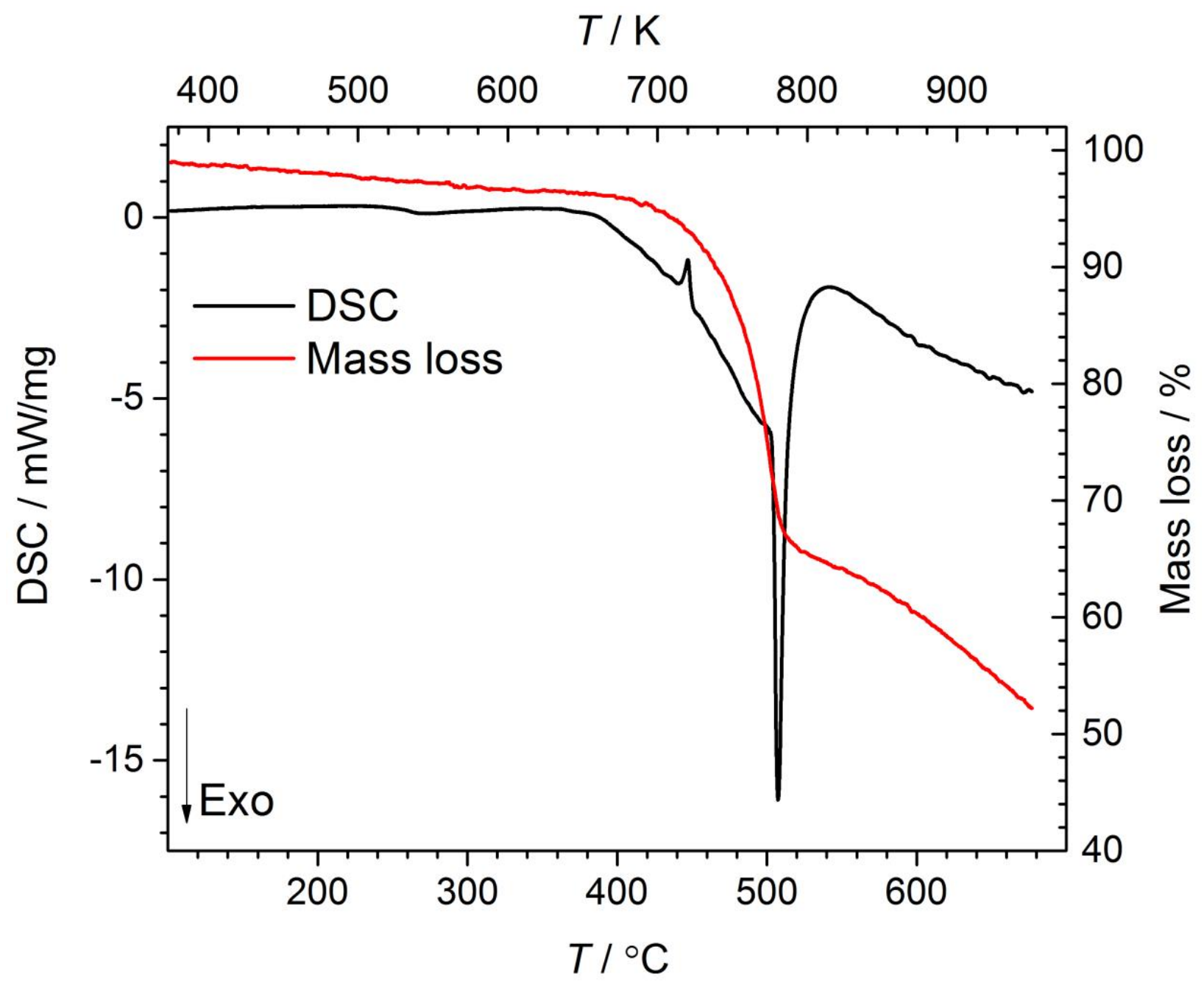

FIG. 5. Thermal analysis of TPP with a heat rate $10 \mathrm{~K} / \mathrm{min}$

\section{Vapor pressure}

The measured ion currents were converted into the vapor pressures $(p)$ (Table I) using the standard KEMS equation

$$
p=k I T,
$$

where $k$ is the mass spectrometer sensitivity constant, $I$ is the total ion current of all ions formed from the TPP molecule, $T$ is the temperature of the Knudsen cell. 
The sensitivity constant $k$ was calculated as $k=p /(I T)$, based on the TPP vapor pressure found in isothermal mass loss experiment according to the Hertz-Knudsen equation

$$
p=\frac{\Delta m}{\Delta t} \cdot \frac{1}{c A} \sqrt{\frac{2 \pi R T}{M}},
$$

where $\Delta m / \Delta t$ is the mass-loss rate, $c$ is the Clausing factor, $A$ is the area of effusion orifice, $M$ is the molecular weight of TPP, $R$ is the ideal gas constant. The total massloss rate $\Delta m / \Delta t$ was found by weighing the cell with the sample before and after vaporization. The effective area of the effusion orifice $c A$ was determined by formula (2) in a separate experiment carried out for the same cell using $\mathrm{Zn}$ as a reference substance.

The determined vapor pressure $(p)$ of TPP was approximated by the linear equation

$$
\ln p / P a=-(23.45 \pm 0.26) \cdot 103 / T+(37.32 \pm 0.47), \quad(\Delta T=490-615 \mathrm{~K}) .
$$

In Fig. 8 the available literature data on TPP vapor pressure are compared. One can see that the values of TPP pressure of different authors agree well to each other at temperatures about $610-620 \mathrm{~K}$. At the same time, the slopes of their temperature trends disagree significantly. Moreover, the temperature dependences in 6,7 have an evidently expressed non-linear character. Note that our data were obtained in the wider low-temperature range.

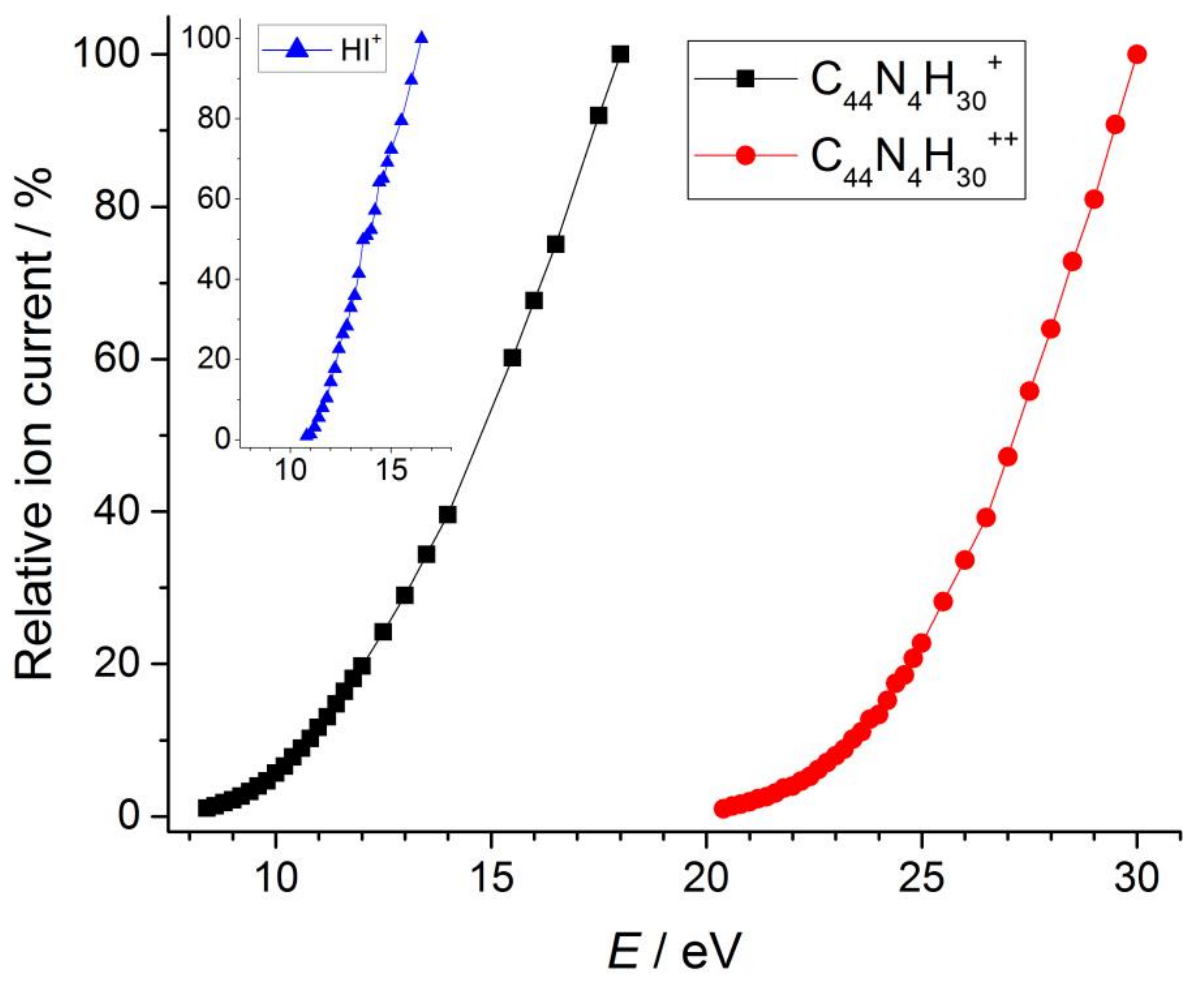

FIG. 6. Ionization efficiency curves 


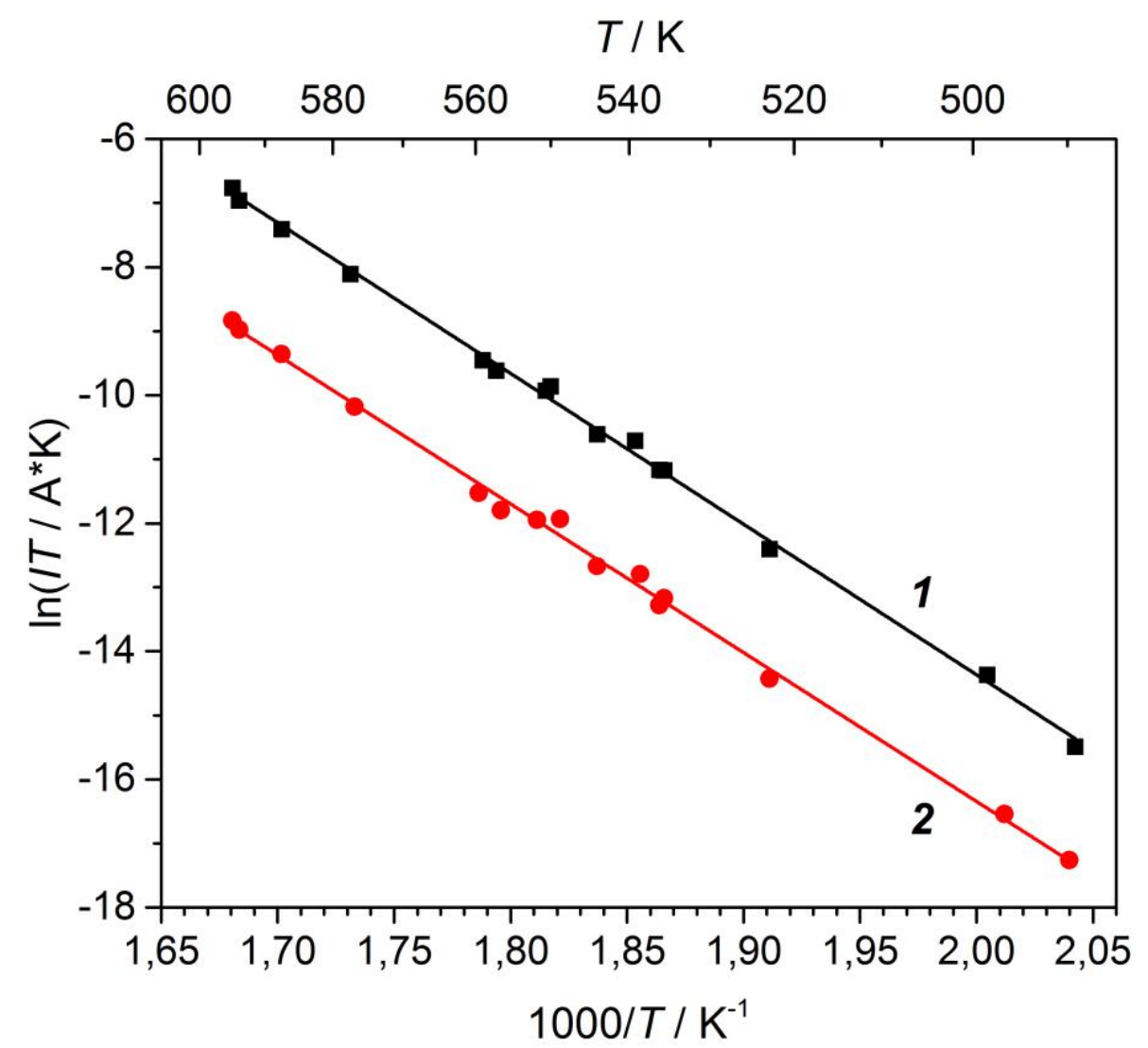

FIG. 7. Temperature dependencies of ion currents:

$1-\ln I\left(\mathrm{C}_{44} \mathrm{~N}_{4} \mathrm{H}_{30+}\right) \cdot T=(-23.54 \pm 0.29) \cdot 10_{3} / T+32.71 \pm 0.53$

$2-\ln I\left(\mathrm{C}_{44} \mathrm{~N}_{4} \mathrm{H}_{30++}\right) \cdot T=(-23.24 \pm 0.33) \cdot 103 / T+30.14 \pm 0.61$

TABLE I. Saturated vapor pressures1 of TPP

\begin{tabular}{cccc}
\hline$T / \mathrm{K}$ & $p / \mathrm{Pa}$ & $T / \mathrm{K}$ & $p / \mathrm{Pa}$ \\
\hline 595 & $1.34 \cdot 10_{-1}$ & 537 & $1.62 \cdot 10_{-3}$ \\
594 & $1.10 \cdot 10_{-1}$ & 544 & $2.86 \cdot 10_{-3}$ \\
550 & $6,04 \cdot 10_{-3}$ & 557 & $7.63 \cdot 10_{-3}$ \\
551 & $5.60 \cdot 10_{-3}$ & 560 & $9.08 \cdot 10_{-3}$ \\
539 & $2.56 \cdot 10_{-3}$ & 577 & $3.48 \cdot 10_{-2}$ \\
536 & $1.64 \cdot 10_{-3}$ & 588 & $7.00 \cdot 10_{-2}$ \\
498 & $6.59 \cdot 10_{-5}$ & 615 & $4.85 \cdot 10_{-1}$ \\
490 & $2.26 \cdot 10_{-5}$ & 612 & $3.33 \cdot 10_{-1}$ \\
523 & $4.77 \cdot 10_{-4}$ & & \\
\hline
\end{tabular}

1The overall uncertainty is estimated by a factor of 2 . 


\section{Sublimation enthalpy}

The vapor pressures allow to calculate the sublimation enthalpy of TPP using approaches of the second and third laws of thermodynamics.

The second law calculation is based on the Clausius-Clapeyron equation

$$
\ln p / p^{\circ}=-\frac{\Delta_{S} H^{\circ}(T)}{R T}+\frac{\Delta_{S} S^{\circ}(T)}{R},
$$

where $p^{\circ}=0.1 \mathrm{MPa}$ is a standard pressure, $\Delta_{s} H^{\circ}(T)$ and $\Delta_{\mathrm{s}} S^{\circ}$ are the enthalpy and entropy of sublimation. It is important to emphasize that in this method the sublimation enthalpy for the average temperature range can be determined from the slope of temperature dependence not only for absolute vapor pressure but also for any experimentally measured quantity, proportional to pressure.

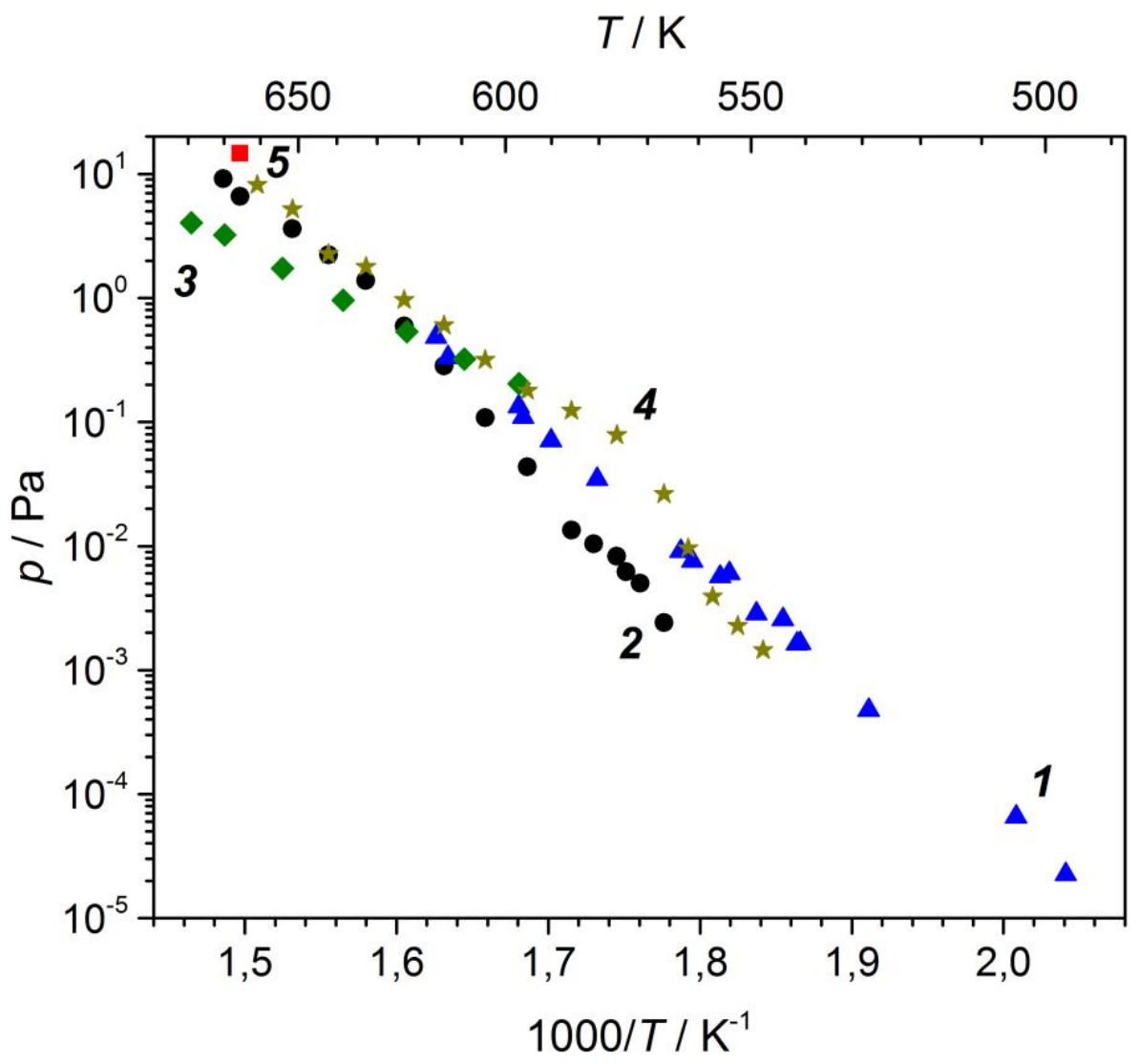

FIG. 8. Temperature dependence of TPP vapor pressure (polymorphic modification is given in parentheses): 1 - triclinic (our data); 2 - tetragonal7; 3 - not specified 3 ; 4 - triclinic6; 5 - presumably tetragonal 4 
The calculations according to the third law are performed using absolute vapor pressures in accordance with the equation

$$
\Delta_{s} H^{\circ}(298.15 \mathrm{~K})=T\left(\Delta_{s} \Phi^{\circ \prime}(T)-R \ln p / p^{\circ}\right),
$$

where $\Phi^{\circ \prime}=-\left(G^{\circ}(T)-H^{\circ}(298.15 \mathrm{~K})\right) / T$ is a reduced Gibbs energy.

The thermodynamic functions of TPP in the gas and crystalline phases, necessary for these calculations, were obtained from quantum chemical computations and experimental measurements of heat capacity (see below).

The results of processing of all the experimental data are given in Table II. As can be seen, the $\Delta_{s} H^{\circ}$ and $\Delta_{s} S^{\circ}$ values obtained by the different authors are largely scattered. The observed deviations are far beyond of the limits of the evaluated errors. Let us try to analyze the possible causes of such strong discrepancies. As for the second law values, there are many different factors such as: a sample purity, type of crystal lattice, magnitude of temperature range studied, thermal stability of crystal phase, etc., which turn out a noticeable effect on the value of sublimation enthalpy. According to the authors of 22,23 , recrystallization of TPPs from a solution leads, depending on the solvent, to the formation of porphyrin sponges (clathrate lattices) of various polymorphic modifications. Therefore, it is important to conduct a preliminary control of the crystalline phase of the studied samples, which was not done, with exception of this work, by the authors of the works discussed here. The enthalpy of sublimation obtained by Golubchikov et al.6 for triclinic $\left(\Delta_{s} H^{\circ}(578 \mathrm{~K})\right.$ $=207 \pm 10 \mathrm{~kJ}$ mol-1) and Perlovich et al.7 for tetragonal $\left(\Delta_{s} H^{\circ}(588 \mathrm{~K})=240 \pm 7 \mathrm{~kJ}\right.$ mol) modifications should be considered as rough estimates due to the mentioned above nonlinearity of temperature dependences. The enthalpy of sublimation $\Delta_{s} H^{\circ}(550 \mathrm{~K})=171 \pm 2 \mathrm{~kJ}$ mol-1, determined by Torres et al.8, cannot be considered to be reliable due to too narrow temperature range $(12 \mathrm{~K})$. In the work4 the temperature range in which the measurements were performed is missing, and the absolute vapor pressure is given only at one temperature $(T=668 \mathrm{~K})$. The sublimation enthalpies obtained in 3,9,10 do not have a definite meaning since it is unclear which TPP modification they relate to. At the same time it should be noted, that for the results with known or suggested TPP modification (this work and the data4,6,7,8), no relation between the sublimation enthalpy and modification is observed.

Processing according to the third law, based on absolute vapor pressure, was performed for the data from $3,4,6,7$ and this work. Since the vapor pressures for different authors agree with each other within one order of magnitude, the third law enthalpies are also close and lie in the range of 212-220 kJ mol-1. At the same time, comparison of $\Delta_{\mathrm{s}} H^{\circ}(298.15 \mathrm{~K})$ and $\Delta_{\mathrm{s}} S^{\circ}(T)$ calculated according to the third and second laws shows a good agreement only for our data, in contrast to literature data, where they either disagree 3,4 or their concordance much worse6,7. Moreover, as can be seen from Fig. 9, a weak temperature trend of the third law value $\Delta_{s} H^{\circ}(298.15 \mathrm{~K})$ 
is observed in the case of our data unlike the data from3,6,7. This indicates a high reliability of the values obtained in this work. Thus, all of the above allows us to recommend the value $\Delta_{s} H^{\circ}(298.15 \mathrm{~K})=220 \pm 12 \mathrm{~kJ}$ mol-1 for the trigonal form of TPP. The overall error given with a " \pm " sign includes statistical (standard deviation) and systematic uncertainties ( $5 \%$ from $\Delta_{s} H^{\circ}$ value).

\section{E. Thermodynamic functions}

\section{The thermodynamic functions of TPP in the solid state}

The thermodynamic functions of TPP in the solid state (Table III) were calculated based on measurements of specific heat capacity (Fig. 10, Table SI in Supplementary Material). In our opinion, a small peak in the range from 270 to $280 \mathrm{~K}$ can be caused by the presence of water, sorbed by the sample when loaded into the effusion cell under atmospheric conditions. The experimental data $C_{p}$ in the temperature range 300-700 K, used in calculations of thermodynamic functions, were approximated by the equation

$$
C_{p} /\left(\mathrm{J} \cdot \mathrm{mol}^{-1} \cdot \mathrm{K}^{-1}\right)=-90.32+2.830 * T-7.161 * 10^{-4} * T^{2}
$$

The standard absolute entropy $S^{\circ}(298.15 \mathrm{~K})=679 \mathrm{~J}$ mol-1 K-1) was estimated using the correlation equation from 24 and The standard absolute entropy $S^{\circ}(298.15 \mathrm{~K})=$ $679 \mathrm{~J} \cdot \mathrm{mol}_{-1} \cdot \mathrm{K}_{-1}$ ) estimated by the correlation equation 24

$$
S^{o}(298.15 \mathrm{~K})_{\text {solid }} /\left(\mathrm{J} \cdot \mathrm{mol}^{-1} \cdot \mathrm{K}^{-1}\right)=1.285\left[\frac{M}{\rho} /\left(\mathrm{cm}^{3} \cdot \mathrm{mol}^{-1}\right)\right]+57
$$

\section{The thermodynamic functions of TPP in an ideal gas state}

The thermodynamic functions of TPP in an ideal gas state were obtained from density functional theory (DFT) simulations. All spatial molecular structures were exposed to geometry optimization with the hybrid generalized gradient approximation (GGA) functional of Perdew and co-workers PBE025,26,27 using the Gaussian 09 software 28. The choice of the PBE0 is attributed to low errors obtained for this particular DFT model in reproducing of experimental molecular geometries free from collective interactions29,30,31. The def2- tzvp32 sets of nuclear-centered Gaussian functions developed in the Karlsruhe group were employed for all the elements. Built-in Gaussian 09 criteria were applied for the convergence of the selfconsistent-field (SCF) scheme. The "tight" internal Gaussian 09 geometry optimization stopping criteria were utilized: maximum gradient $=1.5 \cdot 10_{-5}$ a.u., RMS gradient $=1.0 \cdot 10_{-5}$ a.u., maximum displacement $=6.0 \cdot 10_{-5} \AA$, and RMS displacement $=4.0 \cdot 10_{-5} \AA$. The exchange-correlation potential was integrated numerically using the "ultrafine" pruned grid (99 radial shells and 590 angular points per shell) to get rid of any numerical noise. All optimized spatial structures were 
indicated as stable potential energy surface (PES) minima by the eigenvalues of the electronic energy second derivatives matrix computed analytically.

On basis of calculated molecular parameters (Table S2, S3 in Supplementary Material) the thermodynamic functions of TPP in the state of ideal gas were computed in the "Rigid Rotator - Harmonic Oscillator" (RRHO) approximation by the StatThermo software33. The calculations were performed for the ground electronic state of TPP. A preliminary estimate of the contribution of the low-lying excited electronic states as has been shown to be negligible. The molecule of TPP refers to a point group of symmetry $C_{2 v}$. However, because of $\mathrm{NH}$ tautomerism5,34, the two central hydrogen atoms are distributed between the four nitrogen atoms so quickly that it cannot be detected in NMR experiments. Thus, from this point of view, the TPP molecule can be formally attributed to the symmetry group $C_{4 v}$. For this reason, the symmetry number $\sigma=4$ was used in the calculations. The thermodynamic functions of the TPP molecule were computed in the range of 298$700 \mathrm{~K}$ and are shown in Table III.

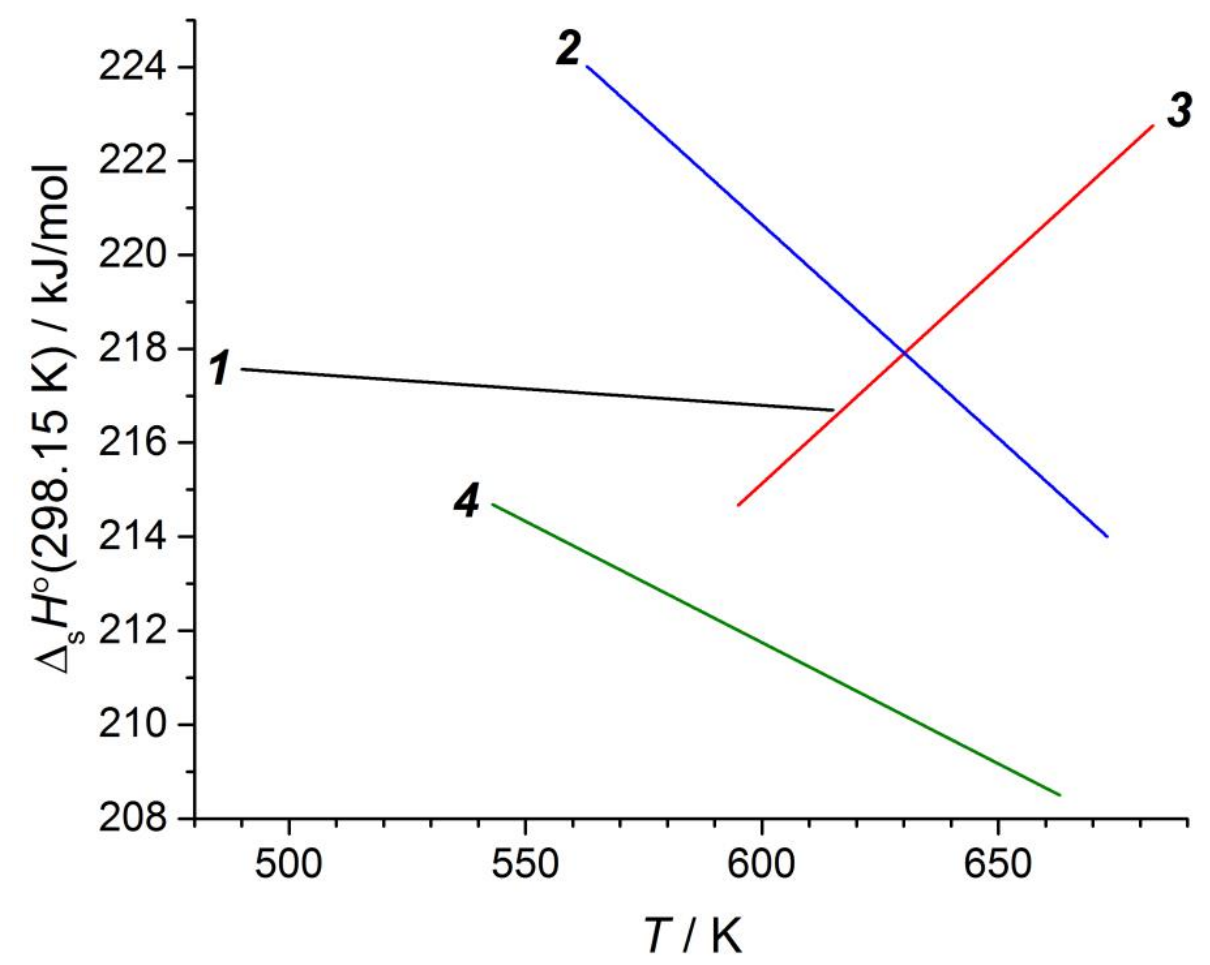

FIG. 9. Dependence of the third law sublimation enthalpy of TPP versus the temperature: 1 - our data; $2 ; 3 ; 4$ - the works7,3,6 respectively 


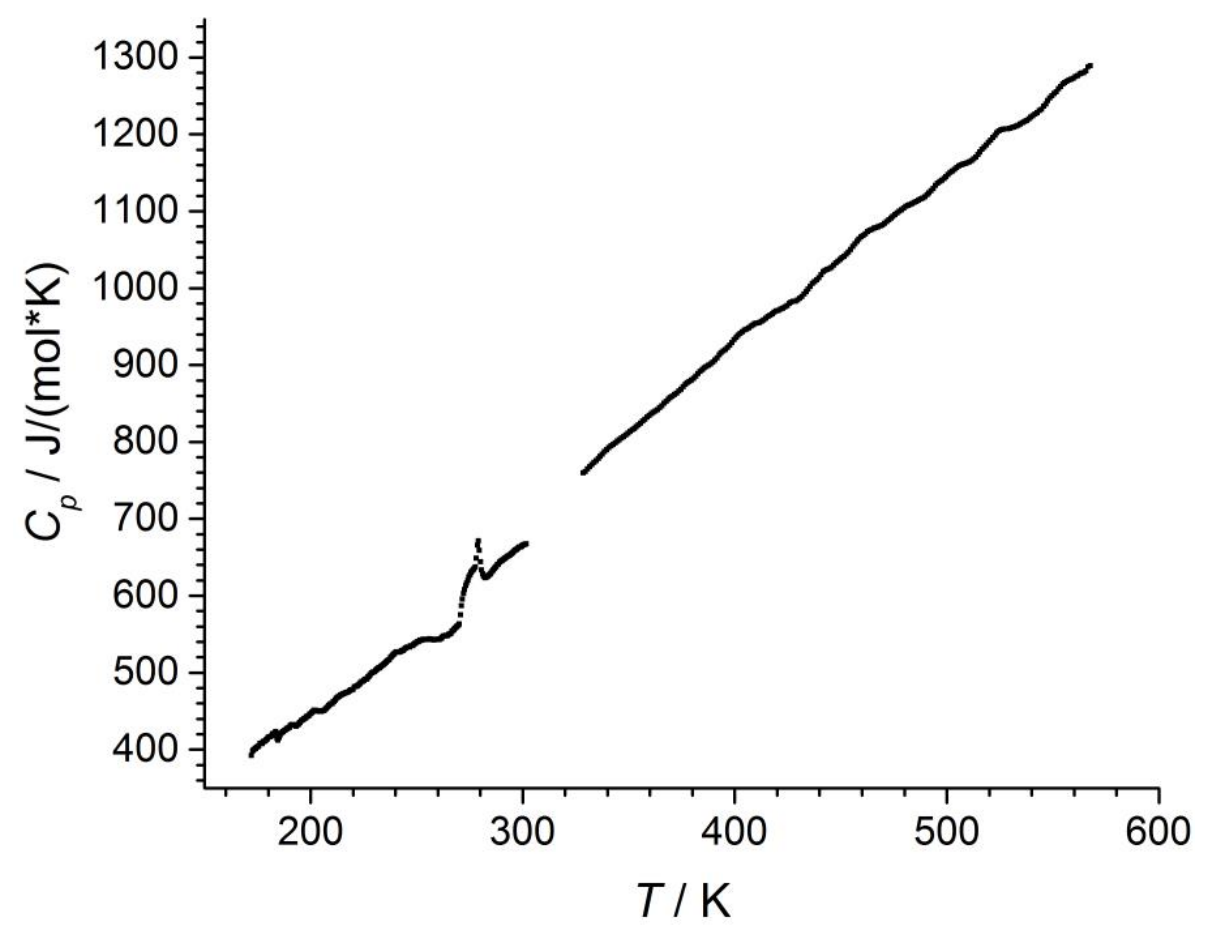

FIG. 10. Temperature dependence of the heat capacity of TPP 
Table II. Enthalpies $\Delta_{\mathrm{s}} H^{\circ}\left(\mathrm{kJ} \cdot \mathrm{mol}_{-1}\right)$ and entropies $\Delta_{\mathrm{s}} S^{\circ}\left(\mathrm{J} \cdot \mathrm{mol}_{-1} \mathrm{~K}_{-1}\right)$ of TPP sublimation

\begin{tabular}{|c|c|c|c|c|c|c|c|c|c|}
\hline \multirow{2}{*}{$\Delta T / \mathrm{K}$} & \multirow{2}{*}{$<T>/ \mathrm{K}$} & \multicolumn{3}{|c|}{ II lawa } & \multicolumn{2}{|c|}{ III lawb } & \multirow{2}{*}{ Modification } & \multirow{2}{*}{ Methodc } & \multirow{2}{*}{ Ref. } \\
\hline & & $\Delta_{s} H^{\circ}(T)$ & $\Delta_{s} S^{\circ}(T)$ & $\Delta s H^{\circ}(298.15) \mathrm{d}$ & $\Delta_{s} H^{\circ}(298.15)$ & $\Delta s S^{\circ}(T)$ & & & \\
\hline $490-615$ & 557 & $195 \pm 2$ & $214 \pm 4$ & $220 \pm 2$ & $217 \pm 60$ & $207 \pm 60$ & triclinic & KEMS & This work \\
\hline $573-673$ & 578 & $207 \pm 10$ & $243 \pm 15$ & $245 \pm 10$ & $212 \pm 60$ & $195 \pm 60$ & triclinic & IGF & [6] \\
\hline $543-555$ & 550 & $171 \pm 2$ & & $197 \pm 2$ & & & $\begin{array}{l}\text { presumably } \\
\text { triclinic }\end{array}$ & $\mathrm{KE}$ & {$[8]$} \\
\hline \multirow[t]{2}{*}{$543-633$} & 588 & $240 \pm 7$ & $278 \pm 10$ & $275 \pm 7$ & $220 \pm 60$ & $191 \pm 60$ & tetragonal & IGF & {$[7]$} \\
\hline & 668 & 146 & & 196 & $212 \pm 60$ & & $\begin{array}{l}\text { presumably } \\
\text { tetragonal }\end{array}$ & VPAS & {$[4]$} \\
\hline $588-678$ & 633 & $111 \pm 5$ & $87 \pm 3$ & $152 \pm 5$ & $219 \pm 60$ & $180 \pm 60$ & not specified & $\mathrm{KE}$ & {$[3]$} \\
\hline $626-707$ & 667 & $142 \pm 3$ & & $191 \pm 3$ & & & not specified & FMDB & {$[9]$} \\
\hline $618-665$ & 642 & $160 \pm 3$ & & $203 \pm 3$ & & & not specified & IGF & {$[10]$} \\
\hline
\end{tabular}

a A standard deviation is given with the " \pm " sign.

b Evaluation of the systematic error is given with the " \pm " sign. The latter is mainly determined by the uncertainty of thermodynamic functions.

c Methods: KE is the Knudsen effusion, VPAS vapor phase absorption spectroscopy, IGF inert gas flow, FMDB fluorescence on molecular diluted beams, KEMS Knudsen effusion mass spectrometry.

d The literature data of $\Delta_{s} H^{\circ}(T)$ were recalculated onto $\Delta_{s} H^{\circ}(298.15)$ using thermodynamic function from this work (see Table III). 
Table III. Thermodynamic functions of TPP

\begin{tabular}{|c|c|c|c|c|c|c|}
\hline \multirow{2}{*}{$T / \mathrm{K}$} & $S^{\circ}$ & $\Phi^{\circ \prime}$ & $H^{\circ}(T)-H^{\circ}(298.15)$ & $S^{\circ}$ & $\Phi^{\circ \prime}$ & $H^{\circ}(T)-H^{\circ}(298.15)$ \\
\hline & \multicolumn{2}{|c|}{$\mathrm{J} \cdot \mathrm{mol}_{-1} \cdot \mathrm{K}_{-1}$} & $\mathrm{~kJ} \cdot \mathrm{mol}_{-1}$ & \multicolumn{2}{|c|}{$\mathrm{J} \cdot \mathrm{mol}_{-1} \cdot \mathrm{K}_{-1}$} & $\mathrm{~kJ} \cdot \mathrm{mol}_{-1}$ \\
\hline & \multicolumn{3}{|c|}{ gas } & \multicolumn{3}{|c|}{ crystal } \\
\hline 298.15 & 946.8 & 946.5 & 0.0 & 679.0 & 679.0 & 0.0 \\
\hline 400 & 1160.7 & 973.8 & 75.4 & 915.7 & 709.1 & 82.5 \\
\hline 500 & 1369.3 & 1032.3 & 167.9 & 1145.8 & 773.4 & 186.2 \\
\hline 600 & 1567.2 & 1105.0 & 276.2 & 1373.0 & 854.5 & 311.1 \\
\hline 700 & 1753.4 & 1184.4 & 398.3 & 1595.4 & 944.5 & 455.7 \\
\hline
\end{tabular}

The uncertainties in the thermodynamic functions were estimated as 5\% in accordance with the procedure discussed in Ref.35. 


\section{F. TPP gas phase formation enthalpy}

The TPP heat of formation in an ideal gas state was derived via the reactionbased methodology 36,37 . In this approach, the TPP heat of formation is expressed through the difference between accurate reference heats of formation and enthalpy change of ad hoc composed chemical reactions. The next reference $\Delta_{f} H^{\circ}(298.15)$ data in kJ.mol-1 retrieved from the Active Thermochemical Tables at Argonne national laboratory web-page 38 were utilized in our research: $228.26 \pm 0.13\left(\mathrm{C}_{2} \mathrm{H}_{2}\right)$, $52.36 \pm 0.12\left(\mathrm{C}_{2} \mathrm{H}_{4}\right),-45.56 \pm 0.03\left(\mathrm{NH}_{3}\right), 88.34 \pm 0.62\left(\mathrm{CH}_{3} \mathrm{~N}\right), 129.27 \pm 0.09(\mathrm{HCN})$, $83.11 \pm 0.23\left(\mathrm{C}_{6} \mathrm{H}_{6}\right), 50.01 \pm 0.34\left(\mathrm{C}_{7} \mathrm{H}_{8}\right)$. For pyrrole the experimental gas phase heat of formation of $108.3 \pm 0.5 \mathrm{~kJ}$ mol-1 39 was adopted as it reasonably matches the theoretically predicted value of $109.2 \pm 2.3 \mathrm{~kJ} \mathrm{~mol}_{-1} 40$.

Total theoretical reaction enthalpies $\left(\Delta_{r} H^{\circ}\right)$ at $298.15 \mathrm{~K}$ were calculated from the following modified Feller-Peterson-Dixon (FPD) method $41,42,43,44,45,46$ presented in equation (7) with $\Delta$ referring to the difference between the reactants and products for each enthalpy component:

$$
\Delta_{r} H^{0}(298.15 \mathrm{~K})=\Delta E_{C B S}+\Delta H_{C O R R}+\Delta E_{A U G}+\Delta E_{C V}+\Delta E_{I T}+\Delta E_{P N O}
$$

The $\Delta E_{C B S}$ term was evaluated as a difference between the single-point (SP) energies of the reactants and the products. All SP energies were obtained with the domain based local pair natural orbital (DLPNO) coupled cluster CCSD(T) approach, $47,48,49$ as a part of the ORCA software. 50 The DLPNO-CCSD(T) approach yielded more accurate enthalpies of reactions comparing to popular DFT models.51,52 The default "NormalPNO" DLPNO settings were adopted. Triple and quadruple- $\zeta$ correlation consistent Gaussian nuclear centered basis sets were employed. Hydrogen, carbon and nitrogen atoms were described with the Gaussian-type cc-pVnZ basis sets of Dunning 53 . Only valence electrons of H, C, N were correlated following the "frozen core" ORCA defaults. The extrapolation to an infinite basis set was performed separately for the HF and the $\operatorname{CCSD}(\mathrm{T})$ correlation energies using the two-point (TZ/QZ) scheme proposed by Helgaker and co-authors. $54,55,56$

Additional corrections to the DLPNO-CCSD(T)/CBS reaction energy $\Delta E_{C B S}$ are requested to attain higher accuracy. The PBE0/def2-tzvp molecular spatial structures and unscaled harmonic vibrational frequencies were exerted to compute the enthalpic correction $\left(H_{C O R R}\right)$ for all individual compounds. The impact of diffuse functions on reaction energies, $\Delta E_{A U G}$, was estimated via the difference in DLPNO-CCSD $(T)$ reaction energies obtained with aug-cc-pVTZ and cc-pVTZ basis sets. The core-valence energy correction on reaction energies, $\Delta E_{C V}$, was approximated by the difference in DLPNO-CCSD $(\mathrm{T})$ reaction energies obtained with cc-pwCVTZ basis sets (cc-pVTZ on H) and all electrons (AE) correlated, and 
cc-pVTZ basis sets and the default "frozen core" framework. The effect of iterative triples correction on reaction energies, $\Delta E_{I T}$, was estimated via the difference in DLPNO-CCSD(T1) reaction energies obtained with iterative (T1) and the default DLPNO-CCSD(T) with semi-canonical (T) and cc-pVTZ basis sets. Finally, the impact of tighter PNO settings, $\Delta E_{P N O}$, was estimated via comparison DLPNO-CCSD $(\mathrm{T}) / \mathrm{cc}-\mathrm{pVTZ}$ reaction energies obtained with TightPNO (TCutPairs $=10_{-5}$, TCutPNO $=10_{-7}$, and TCutMKN $=10_{-3}$ ) and default NormalPNO settings. For all but the AE simulations, the correlation fitting basis sets ((aug-)cc-pVnZ/C) worked out by Hättig et al.s7 mandatory for the resolution of identity (RI) approximation which is at root of the DLPNO approach were utilized. The AutoAux58 option was employed for automatic initiation of correlation fitting Gaussian basis sets requested for for the AE computations. The ideal gas TPP formation enthalpies are collected in Table IV.

An analysis of Table IV reveals that the largest impact on reaction energies were obtained from inclusion of diffuse Gaussian functions $\left(\Delta E_{A U G}\right)$ and using of iterative (T1) triples instead their semi-canonical counterparts, $\Delta E_{I T}$. The significance of core-valence correction $\left(\Delta E_{C V}\right)$ and tightening of PNO frameworks $\left(\Delta E_{P N O}\right)$ were both noticed to be less important. The resulting heats of formation were detected to vary considerably on chemical reaction applied. The averaged over 10 reactions $\Delta H_{f}^{\circ}(298.15 \mathrm{~K})$ amounts $1004 \pm 10 \mathrm{~kJ}$ mol-1 (a doubled standard deviation is accepted as an error).

\section{G. Enthalpy of formation of TPP in crystal state}

The standard values of formation enthalpy of crystalline TPP were experimentally determined in works59,60,61. The first of these $\Delta_{f} H^{\circ}(298.15 \mathrm{~K})=$ $621.3 \pm 8.5 \mathrm{~kJ} \cdot \mathrm{mol}_{-1}$ was obtained by $\mathrm{Wu}$ et al.59 in 1989 using static bomb calorimeter. Then in 1999 Patino et al.60 using combustion calorimeter measured the standard molar energy of combustion and calculated the formation enthalpy $\Delta_{f} H^{\circ}(298.15 \mathrm{~K})=655 \pm 9 \mathrm{~kJ} \cdot \mathrm{mol}_{-1}$. The last value $\Delta_{f} H^{\circ}(298.15 \mathrm{~K})=1174.8 \pm 33.7$ $\mathrm{kJ} \cdot \mathrm{mol}_{-1}$ from work61 was calculated from the enthalpy of combustion found by the liquid calorimetry with isothermal shell. It is obvious that all the above results contradict to each other.

In this work, the formation enthalpy of crystalline TPP was obtained as the difference between the gas phase formation enthalpy and the enthalpy of sublimation. Our value $\Delta_{f} H^{\circ}(298.15 \mathrm{~K})=784 \pm 15 \mathrm{~kJ} \cdot \mathrm{mol}_{-1}$ is within the range of the above literature values59,60,61. 
TABLE IV. Enthalpies of formation of TPP in the gaseous state as well as corresponding reaction enthalpies along with individual contributions in $\mathrm{kJ}$ mol-1.

\begin{tabular}{|c|c|c|c|c|c|c|c|c|c|}
\hline $\mathrm{N}$ & Reaction & $\Delta E_{\mathrm{CBS}}$ a & $\Delta E_{\mathrm{AUG}} \mathrm{b}$ & $\Delta E_{\mathrm{CV} \text { с }}$ & $\Delta E_{\mathrm{IT} \mathrm{d}}$ & $\Delta E_{\mathrm{PNO}} \mathrm{e}$ & $\begin{array}{l}\Delta H_{\mathrm{CORR} f} \\
(298.15)\end{array}$ & $\begin{array}{c}\Delta H_{\mathrm{r}^{\circ}} \\
(298.15)\end{array}$ & $\begin{array}{c}\Delta H_{f}^{\circ} \\
(298.15)\end{array}$ \\
\hline 1 & $4 \mathrm{C}_{6} \mathrm{H}_{6}+10 \mathrm{C}_{2} \mathrm{H}_{4}+2 \mathrm{~N}_{2}=\mathrm{C}_{44} \mathrm{H}_{30} \mathrm{~N}_{4}+17 \mathrm{H}_{2}$ & 484.6 & -51.8 & -5.1 & -20.5 & -1.8 & -282.8 & 122.5 & 978.6 \\
\hline 2 & $7 \mathrm{C}_{6} \mathrm{H}_{6}+\mathrm{C}_{2} \mathrm{H}_{2}+4 \mathrm{NH}_{3}=\mathrm{C}_{44} \mathrm{H}_{30} \mathrm{~N}_{4}+13 \mathrm{H}_{2}$ & 677.3 & -9.6 & -1.9 & -15.9 & 0.9 & -247.9 & 402.9 & 1030.7 \\
\hline 3 & $6 \mathrm{C}_{6} \mathrm{H}_{6}+2 \mathrm{C}_{2} \mathrm{H}_{4}+4 \mathrm{HCN}=\mathrm{C}_{44} \mathrm{H}_{30} \mathrm{~N}_{4}+9 \mathrm{H}_{2}$ & 52.6 & -46.0 & 1.8 & -14.2 & 0.7 & -125.6 & -130.7 & 989.8 \\
\hline 4 & $4 \mathrm{C}_{6} \mathrm{H}_{6}+4 \mathrm{C}_{4} \mathrm{NH}_{5}+2 \mathrm{C}_{2} \mathrm{H}_{4}=\mathrm{C}_{44} \mathrm{H}_{30} \mathrm{~N}_{4}+11 \mathrm{H}_{2}$ & 391.5 & -24.4 & -0.4 & -16.7 & 3.5 & -211.6 & 141.8 & 1012.2 \\
\hline 5 & $4 \mathrm{C}_{6} \mathrm{H}_{6}+4 \mathrm{C}_{4} \mathrm{NH}_{5}+2 \mathrm{C}_{2} \mathrm{H}_{2}=\mathrm{C}_{44} \mathrm{H}_{30} \mathrm{~N}_{4}+9 \mathrm{H}_{2}$ & -21.9 & -24.7 & 2.3 & -15.6 & 3.0 & -154.1 & -211.0 & 1011.2 \\
\hline 6 & $4 \mathrm{C}_{7} \mathrm{H}_{8}+4 \mathrm{C}_{4} \mathrm{NH}_{5}=\mathrm{C}_{44} \mathrm{H}_{30} \mathrm{~N}_{4}+11 \mathrm{H}_{2}$ & 641.0 & -17.2 & -0.8 & -16.8 & 5.4 & -228.5 & 383.0 & 1016.3 \\
\hline 7 & $4 \mathrm{C}_{7} \mathrm{H}_{8}+4 \mathrm{CH}_{2} \mathrm{NH}+6 \mathrm{C}_{2} \mathrm{H}_{4}=\mathrm{C}_{44} \mathrm{H}_{30} \mathrm{~N}_{4}+19 \mathrm{H}_{2}$ & 545.1 & -27.9 & -11.0 & -21.2 & 0.5 & -354.3 & 131.2 & 998.8 \\
\hline 8 & $4 \mathrm{C}_{7} \mathrm{H}_{8}+4 \mathrm{CH}_{2} \mathrm{NH}+6 \mathrm{C}_{2} \mathrm{H}_{2}=\mathrm{C}_{44} \mathrm{H}_{30} \mathrm{~N}_{4}+13 \mathrm{H}_{2}$ & -695.0 & -28.7 & -3.1 & -17.8 & -0.7 & -181.8 & -927.1 & 995.9 \\
\hline 9 & $6 \mathrm{C}_{6} \mathrm{H}_{6}+2 \mathrm{C}_{2} \mathrm{H}_{4}+4 \mathrm{CH}_{3} \mathrm{~N}=\mathrm{C}_{44} \mathrm{H}_{30} \mathrm{~N}_{4}+13 \mathrm{H}_{2}$ & 336.1 & -31.8 & -6.5 & -16.5 & 1.2 & -236.8 & 45.7 & 1002.4 \\
\hline \multirow[t]{2}{*}{10} & $6 \mathrm{C}_{6} \mathrm{H}_{6}+2 \mathrm{C}_{2} \mathrm{H}_{2}+4 \mathrm{CH}_{3} \mathrm{~N}=\mathrm{C}_{44} \mathrm{H}_{30} \mathrm{~N}_{4}+11 \mathrm{H}_{2}$ & -77.3 & -32.0 & -3.8 & -15.4 & 0.7 & -179.3 & -307.1 & 1001.5 \\
\hline & & & & & & & & Average & $1004 \pm 5 \mathrm{~g}$ \\
\hline
\end{tabular}

a $\triangle E$ DLPNO-CCSD(T) reaction energy obtained from cc-pVTZ/cc-pVQZ CBS extrapolation; b the effect of diffuse functions obtained as a difference between DLPNO-CCSD(T)/aug-cc-pVTZ and DLPNO-CCSD(T)/cc-pVTZ reaction energies; c the effect of core-valence correlation obtained as a difference between AE DLPNO-CCSD(T)/cc-pwCVTZ (cc-pVTZ on H) and FC DLPNO-CCSD(T)/cc-pVTZ reaction energies; $d$ the effect of iterative triples obtained as a difference between DLPNO-CCSD(T1)/cc-pVTZ and the default DLPNO-CCSD(T)/cc-pVTZ reaction energies; the effect of tightening of PNO settings obtained as a difference between Tight PNO DLPNO-CCSD(T)/cc-pVTZ and Normal PNO DLPNO-CCSD(T)/cc-pVTZ reaction energies; $\mathrm{f}$ the effect of enthalpic correction on reaction energies to arrive at reaction enthalpies; $\mathrm{g}$ a standard deviation is given with the " \pm " sign. 


\section{CONCLUSION}

In the course of a comprehensive investigation of the evaporation of 5,10,15,20tetraphenylporphyrin (TPP), the following new results were obtained:

(1) TPP evaporates congruently in the molecular form $\mathrm{C}_{44} \mathrm{~N}_{4} \mathrm{H}_{30}$ in the temperature range 490-615 K.

(2) TPP begins to decompose at a temperature of about $700 \mathrm{~K}$. The melting temperature and the enthalpy of melting are $720 \pm 6 \mathrm{~K}$ and $17 \pm 5 \mathrm{~kJ} \cdot \mathrm{mol}_{-1}$, respectively.

(3) The saturated vapor pressure was measured and the sublimation enthalpy $\Delta_{s} H^{\circ}(298.15 \mathrm{~K})=220 \pm 12 \mathrm{~kJ}$ mol-1 $_{-1}$ for the triclinic form of TPP was recommended.

(4) The formation enthalpy $\Delta_{f} H^{\circ}(298.15 \mathrm{~K})=1004 \pm 10 \mathrm{~kJ}$ mol-1 of gaseous TPP molecules was determined using a high quality reaction-based Feller-PetersonDixon DLPNO-CCSD(T) approach.

(5) The formation enthalpy of crystalline TPP $\Delta_{f} H^{\circ}(298.15 \mathrm{~K})=784 \pm 15 \mathrm{~kJ}$ was obtained based on the gas phase formation enthalpy and the enthalpy of sublimation.

(6) The specific heat capacity of TPP in the solid state was measured and quantumchemical calculations of the structure and force field of TPP molecules were performed. The results obtained made it possible to calculate the thermodynamic functions of TPP in the solid and gaseous states.

\section{SUPPLEMENTARY MATERIAL}

The atomic coordinates, vibrational frequencies and IR-intensities of the TPP molecule obtained as a result of quantum-chemical calculations are summarized in Tables S1, S2 and S3 in Supplementary Material.

\section{ACKNOWLEDGEMENTS}

This work was supported by the Ministry of science and higher education of the Russian Federation in the framework of Government order (№ FZZW-2020-0007).

The authors are grateful to Ph.D. N.L. Pechnikova and Dr. V.V. Aleksandriiskii (Research Sharing Center of the Ivanovo State University of Chemistry and Technology) for the synthesis of TPP and the study of the NMR spectrum, 
respectively, Ph.D. D.V. Tyurin (Department of Chemistry and Technology of Higher Molecular Compounds of the Ivanovo State University of Chemistry and Technology) for the MALDI spectrum of TPP and Ph.D. A.A. Gushchin (Department of Industrial Ecology of the Ivanovo State University of Chemistry and Technology) for the analysis of TPP sample by the high performance liquid chromatography. The authors also thank Ph.D. M.S. Gruzdev (Research Sharing Center of the Institute of Solution Chemistry RAS, Ivanovo) and Ph.D. D.N. Sergeev (Forschungszentrum Jülich, IEK-2, Germany) for measuring the heat capacity of TPP in the temperature ranges $169-302 \mathrm{~K}$ and $328-568 \mathrm{~K}$, respectively.

\section{REFERENCES}

1E.K.M. Kadish, K.M. Smith, and R. Guilard, The Porphyrin Handbook, Academic Press, San Diego, 2003, Vols.1-20.

$2^{2 " C h e m i s t r y ~ o f ~ b i o l o g i c a l l y ~ a c t i v e ~ n a t u r a l ~ c o m p o u n d s ~(c a r b o h y d r a t e-p r o t e i n ~}$ complexes, chromoproteins, lipids, lipoproteins, metabolism)", ed. by N. A. Preobrazhenskij and R. P. Evstigneeva, Chemistry, Moscow, 1976. [in Russian] 3D. Bonderman, E.D. Cater, W.E. Bennett, Vapor pressures, mass spectra, magnetic susceptibilities, and thermodynamics of some phthalocyanine compounds, J. Chem. Eng. Data, 15 (1970), pp. 396-400. DOI: https://doi.org/10.1021/je60046a004 4 L. Edwards, D.H. Dolphin, M. Gouterman, A.D. Adler, Porphyrins XVII. Vapor absorption spectra and redox reactions: tetraphenylporphins and porphin, J. Mol. Spectrosc., 38 (1971), pp. 16-32. DOI: https://doi.org/10.1016/00222852(71)90090-7

5O.A. Golubchikov, G.L. Perlovich, B.K. Naneishvilli, Termodinamika sublimacii tetrafenilporfirina (Sublimation thermodynamics of tetraphenylporphyrin) Zh. Fiz. Khim., 68 (1994), pp. 2120-2123. [in Russian]

6O.A. Golubchikov, G.L. Perlovich, Termodinamika sublimacii porfirinov, In:

"Advances in chemistry of porphyrins", Ed. by Golubchikov O.A., Vol. 1, Ch. 10, St. Petersburg State University, 1997, pp. 223-245. [in Russian]

7G. L. Perlovich, O.A. Golubchikov, M.E. Klueva, Thermodynamics of porphyrin sublimation, J. of Porphir. Phthalocyanines, 4 (2000), pp. 699-706.

DOI: 10.1002/1099-1409(200012)4:8<699:AID-JPP284>3.0.CO;2-M 8 L.A. Torres, M. Campos, E. Enriquez, R. Patino The enthalpy of sublimation of 5,10,15,20-tetraphenylporphine and 5,10,15,20-tetrakis(4methoxyphenyl)porphine, J. Chem. Thermodynamics, 34 (2002), pp. 293-302. DOI: https://doi.org/10.1006/jcht.2001.0920 
9A.A. Stefanov, A. Stibor, A. Dominguez-Clarimon, M. Arndt, Sublimation enthalpy of dye molecules measured using fluorescence, J. Chem. Phys., 121 (2004), pp. 6935-6940. DOI: https://doi.org/10.1063/1.1792551

10S. Deachapunya, A. Stefanov, M. Berninger, H. Ulbricht, E. Reiger, N.L. Doltsin is, M. Arndt, Thermal and electrical properties of porphyrin derivatives and their relevance for molecule interferometry, J. Chem. Phys., 126 (2007), pp. 164304-1164304-7. DOI: https://doi.org/10.1063/1.2721563

11A.S. Semeikin, O.I. Koifman, B.D. Berezin, Improved method for synthesis of substituted tetraphenylporphins Chem. Heterocycl. Compd, 22 (1986) pp. 629632.

${ }_{12}$ S.J. Silvers, A. Tulinsky, The crystal and molecular structure of triclinic tetraphenylporphyrin, J. Amer. Chem. Soc., 89 (1967) pp. 3331-3337. DOI: 10.1021/ja00989a036 13K.M. Smith, D.A. Goff, R.J. Abraham, J.E. Plant, The NMR spectra of porphyrins: 22 - Ring current effects in chlorins versus porphyrins, Org. Magn. Reson., 21 (1983), pp. 505-511. DOI: https://doi.org/10.1002/omr.1270210811. 14J.L. Soret, Analyse spectrale: sur le spectre d'absorption du song dans la partie violette et ultraviolette, Compt. Rend, 97 (1883), pp. 1269-1273. [in French] ${ }_{15}$ M. Biesaga, K. Pyrzynska, M. Trojanowicz, Porphyrins in analytical chemistry. A review., Talanta, 51 (2000), pp. 209-224. DOI: 10.1016/s0039-9140(99)00291-X 16A.M. Pogrebnoi, L.S. Kudin, A.Yu. Kuznetsov, M.F. Butman, Molecular and ionic clusters in saturated vapor over lutetium trichloride, Rapid Commun. Mass Spectrom., 11 (1997), pp. 1536-1546. DOI: https://doi.org/10.1002/(SICI)10970231(199709)11:14<1536:AID-RCM31>3.0.CO;2-D

17A.M. Dunaev, V.B. Motalov, L.S. Kudin, A high-temperature massspectrometric method for determination of the electron work function of ionic crystals: Lanthanum, cerium, and praseodymium triiodides, Russ. J. Gen.

Chem., 87 (2017), pp. 632-638. DOI: 10.1134/S1070363217030410 18A.M. Dunaev, A.S. Kryuchkov, L.S. Kudin, M.F. Butman, Avtomatizirovannyy kompleks dlya vysokotemperaturnykh issledovaniy na baze mass-spektrometra MI1201 (Automated complex for high temperature research based on the mass spectrometer MI1201), Izv. Vyssh. Uchebn. Zaved. Khim. Khim. Tekhnol., 54 (2011), pp. 73-77. [in Russian] ${ }_{19}$ D.N. Sergeev, A.M. Dunaev, D.A. Ivanov, Y.A. Golovkina, G.I. Gusev, Automation of a mass spectrometer for determination of ionization efficiency functions, Russ. Instrum. Exp. Tech., 1 (2014), pp. 139-140.

DOI: $10.7868 / \mathrm{S} 0032816214010200$

${ }_{20}$ G. Della Gatta, M.J. Richardson, S.M. Sarge, S. Stølen, Standards, calibration, and guidelines in microcalorimetry. Part 2. Calibration standards for differential scanning calorimetry (IUPAC Technical Report), Pure Appl. Chem., 78 (2006), pp. 1455-1476. DOI: https://doi.org/10.1351/pac200678071455

${ }_{21}$ K. Kimura, S. Katsumata, Y. Achiba, T. Yamazaki, S. Iwata "Handbook of HeI Photoelectron Spectra of Fundamental Organic Compounds", Japan Scientific Society Press, Tokyo, 1981. 
22O.R. Simonova, V.B. Sheinin. Thermodynamics of Formation of Porphyrin Sponge in the Etioporphyrin III-Methanol System, Russ. J. Gen. Chem. 78 (2008), pp. 1268-1272. DOI: 10.1134/S1070363208060297

23M.P. Byrn, C.J. Curtis, Yu Hsiou, S.I. Khan, P.A. Sawin, S.K. Tendick, A. Terzis, C.E. Strouse. Porphyrin Sponges: Conservation of Host Structure in over 200 Porphyrin-Based Lattice Clathrates, Am. Chem. Soc., 115 (1993), pp. 94809491. DOI: https://doi.org/10.1021/ja00074a013

24L. Glasser, H.D.B. Jenkins, Standard absolute entropies, $S^{\circ} 298$, from volume or density: Part II. Organic liquids and solids, Thermochim. Acta, 414 (2004), pp. 125-130. DOI: https://doi.org/10.1016/j.tca.2003.12.006

25J.P. Perdew, K. Burke, M. Ernzerhof, Generalized Gradient Approximation Made Simple, Phys. Rev. Lett., 77 (1996), pp. 3865-3868. DOI:

https://doi.org/10.1103/PhysRevLett.77.3865

26J.P. Perdew, K. Burke, M. Ernzerhof, Generalized Gradient Approximation Made Simple [Phys. Rev. Lett. 77, 3865 (1996)], Phys. Rev. Lett., 78 (1997), pp. 1396.

DOI: https://doi.org/10.1103/PhysRevLett.78.1396

${ }_{27} \mathrm{C}$. Adamo, V. Barone, Toward reliable density functional methods without adjustable parameters: The PBE0 model, Chem. Phys., 110 (1999), pp. 6158-6170. DOI: https://doi.org/10.1063/1.478522

${ }_{28}$ Gaussian 09, Gaussian / Frisch, M. J.; Trucks, G. W.; Schlegel, H. B.; Scuseria, G. E.; Robb, M. A.; Cheeseman, J. R.; Scalmani, G.; Barone, V.; Mennucci, B.; Petersson, G. A.; Nakatsuji, H.; Caricato, M.; Li, X.; Hratchian, H. P.; Izmaylov, A. F.; Bloino, J.; Zheng, G.; Sonnenberg, J. L.; Hada, M.; Ehara, M.; Toyota, K.; Fukuda, R.; Hasegawa, J.; Ishida, M.; Nakajima, T.; Honda, Y.; Kitao, O.; Nakai, H.; Vreven, T.; Montgomery Jr., J. A.; Peralta, J. E.; Ogliaro, F.; Bearpark, M. J.; Heyd, J.; Brothers, E. N.; Kudin, K. N.; Staroverov, V. N.; Kobayashi, R.; Normand, J.; Raghavachari, K.; Rendell, A. P.; Burant, J. C.; Iyengar, S. S.; Tomasi, J.; Cossi, M.; Rega, N.; Millam, N. J.; Klene, M.; Knox, J. E.; Cross, J. B.; Bakken, V.; Adamo, C.; Jaramillo, J.; Gomperts, R.; Stratmann, R. E.; Yazyev, O.; Austin, A. J.; Cammi, R.; Pomelli, C.; Ochterski, J. W.; Martin, R. L.; Morokuma, K.; Zakrzewski, V. G.; Voth, G. A.; Salvador, P.; Dannenberg, J. J.; Dapprich, S.; Daniels, A. D.; Farkas, Ö.; Foresman, J. B.; Ortiz, J. V.; Cioslowski, J.; Fox, D. J., Inc.: Wallingford, CT, USA, 2009.

29Y. Minenkov, L. Cavallo, Ground-State Gas-Phase Structures of Inorganic Molecules Predicted by Density Functional Theory Methods, ACS Omega, 2 (2017), pp. 8373-8387. DOI: https://doi.org/10.1021/acsomega.7b01203 30I. Minenkova, V.V. Sliznev, L. Cavallo, Y. Minenkov, Gas Phase Silver Thermochemistry from First Principles, Inorg. Chem., 58 (2019), pp. 7873-7885. DOI: https://doi.org/10.1021/acs.inorgchem.9b00556 ${ }_{31}$ G.V. Girichev, N.I. Giricheva, O.I. Koifman, Y.V. Minenkov, A.E Pogonin, A.S. Semeikin, and S.A. Shlykov, Molecular structure and bonding in octamethylporphyrin tin(ii), SnN4C28H28, Dalton Trans., 41 (2012), pp. 75507558. DOI: $10.1039 / \mathrm{C} 2 \mathrm{DT} 12499 \mathrm{H}$ 
${ }_{32} \mathrm{~F}$. Weigend, R. Ahlrichs, Balanced basis sets of split valence, triple zeta valence and quadruple zeta valence quality for $\mathrm{H}$ to $\mathrm{Rn}$ : Design and assessment of accuracy, Phys. Chem. Chem. Phys., 7 (2005), pp. 3297-3305. DOI:

10.1039/B508541A

33A.M. Dunaev, L.S. Kudin, Izv. Vyss. Uchebn. Zaved. Khim. Khim. Tekhnol., 2017, 60, 40-46. https://doi.org/10.6060/tcct.2017604.5490

34 Y. Niwa, H. Kobayashi, T. Tsuchiya, X-ray photoelectron spectroscopy of tetraphenylprophine and phthalocyanine, J. Chem. Phys., 60 (1974), pp. 799-807. DOI: https://doi.org/10.1063/1.1681153

35L.V Gurvich, I.V. Veyts, C.B. Alcock, Thermodynamic properties of individual substances, 4th ed., Vol.1, Hemisphere Publishing Corp., New York, 1989. ${ }_{36}$ D.H. Bross, K.A. Peterson, Composite thermochemistry of gas phase U(VI)containing molecules, J. Chem. Phys., 141 (2014), pp. 244308. DOI:

https://doi.org/10.1063/1.4904721

37 Y. Minenkov, V.V. Sliznev, L. Cavallo, Accurate Gas Phase Formation Enthalpies of Alloys and Refractories Decomposition Products, Inorg. Chem., 2017, 56, 1386-1401, DOI: 10.1021/acs.inorgchem.6b02441.

38B. Ruscic, R.E. Pinzon, G. von Laszewski, D. Kodeboyina, A. Burcat, D. Leahy, D. Montoya, A. F.Wagner, Active Thermochemical Tables:

Thermochemistry for the 21st Century, J. Phys. Conf. Ser., 16 (2005), pp. 561-570. DOI: https://doi.org/10.1088/1742-6596/16/1/078

${ }_{39}$ D.W. Scott, W.T. Berg, Ia Hossenlo, W.N. Hubbard, J.F. Messerly, S.S. Todd, D.R. Douslin, McCullou. Jp, G. Pyrrole Waddingt, Pyrrole: chemical thermodynamic properties, J. Phys. Chem., 71 (1967), pp. 2263-2270. DOI: https://doi.org/10.1021/j100866a046

40J.M. Simmie, A Database of Formation Enthalpies of Nitrogen Species by Compound Methods (CBS-QB3, CBS-APNO, G3, G4), J. Phys. Chem. A., 119 (2015), pp. 10511-10526. DOI: https://doi.org/10.1021/acs.jpca.5b06054 ${ }_{41}$ D. Feller, K.A. Peterson, D.A. Dixon, A survey of factors contributing to accurate theoretical predictions of atomization energies and molecular structures, J. Chem. Phys., 129 (2008), pp. 204105. DOI: https://doi.org/10.1063/1.3008061 ${ }_{42}$ D. Feller, K.A. Peterson, D.A. Dixon, Further benchmarks of a composite, convergent, statistically calibrated coupled-cluster-based approach for thermochemical and spectroscopic studies, Mol. Phys. 110 (2012), pp. 2381-2399. DOI: https://doi.org/10.1080/00268976.2012.684897 ${ }_{43}$ K.A. Peterson, D. Feller, D.A. Dixon, Chemical accuracy in ab initio thermochemistry and spectroscopy: current strategies and future challenges, Theor. Chem. Acc. 131 (2012), pp. 1-20. DOI: https://doi.org/10.1007/s00214-011-1079-5 44D.A. Dixon, D. Feller, K.A. Peterson, Chapter One - A Practical Guide to Reliable First Principles Computational Thermochemistry Predictions across the Periodic Table, Annu. Rep. Comput. Chem., 8 (2012), pp. 1-28. DOI: https://doi.org/10.1016/B978-0-444-59440-2.00001-6 ${ }_{45 D}$. Feller, K.A. Peterson, D.A. Dixon, Chapter Two - The Impact of Larger Basis Sets and Explicitly Correlated Coupled Cluster Theory on the Feller-Peterson- 
Dixon Composite Method, Annu. Rep. Comput. Chem., 12 (2016), pp. 47-78. DOI: https://doi.org/10.1016/bs.arcc.2016.02.001 ${ }_{46} \mathrm{M}$. Vasiliu, D.J. Grant, D. Feller, D.A. Dixon, Heats of Formation of MHxCly $(\mathrm{M}=\mathrm{Si}, \mathrm{P}, \mathrm{As}, \mathrm{Sb})$ Compounds and Main Group Fluorides from High Level Electronic Structure Calculations, J. Phys. Chem. A., 116 (2012), pp. 3717-3727. DOI: https://doi.org/10.1021/jp2119229

${ }_{47}$ C. Riplinger, F. Neese, An efficient and near linear scaling pair natural orbital based local coupled cluster method, J. Chem. Phys., 138 (2013), pp. 034106. DOI: https://doi.org/10.1063/1.4773581

${ }_{48}$ C. Riplinger, B. Sandhoefer, A. Hansen, F. Neese, Natural triple excitations in local coupled cluster calculations with pair natural orbitals, J. Chem. Phys., 139 (2013), pp. 134101. DOI: https://doi.org/10.1063/1.4821834 ${ }_{49}$ C. Riplinger, P. Pinski, U. Becker, E.F. Valeev, F. Neese, Sparse maps-A systematic infrastructure for reduced-scaling electronic structure methods. II. Linear scaling domain based pair natural orbital coupled cluster theory, J. Chem. Phys., 144 (2016), pp. 024109. DOI: https://doi.org/10.1063/1.4939030 50F. Neese, The ORCA program system, WIREs Comput. Mol. Sci., 2 (2012), pp. 73-78. DOI: https://doi.org/10.1002/wcms.81

$5^{1}$ Y. Minenkov, E. Chermak, L. Cavallo, Accuracy of DLPNO-CCSD(T) Method for Noncovalent Bond Dissociation Enthalpies from Coinage Metal Cation Complexes, J. Chem. Theory Comput., 11 (2015), pp. 64-4676, DOI: https://doi.org/10.1021/acs.jctc.5b00584 ${ }_{52}$ R. Credendino, Y. Minenkov, D. Liguori, F. Piemontesi, A. Melchior, G. Morini, M. Tolazzi, L. Cavallo, Accurate experimental and theoretical enthalpies of association of $\mathrm{TiCl}_{4}$ with typical Lewis bases used in heterogeneous ZieglerNatta catalysis, Phys. Chem. Chem. Phys., 19 (2017), pp. 26996-27006, DOI: $10.1039 / \mathrm{c} 7 \mathrm{cp} 04047 \mathrm{~d}$ 53.T.H. Dunning, Gaussian basis sets for use in correlated molecular calculations. I. The atoms boron through neon and hydrogen, J. Chem. Phys., 90 (1989), pp. 10071023. DOI: https://doi.org/10.1063/1.456153

54Halkier, T. Helgaker, P. Jørgensen, W. Klopper, H. Koch, J. Olsen, A.K. Wilson, Basis-set convergence in correlated calculations on Ne, N2, and H2O, Chem. Phys. Lett., 286 (1998), pp. 243-252. DOI: https://doi.org/10.1016/S00092614(98)00111-0

${ }_{55}$ T. Helgaker, W. Klopper, H. Koch, J. Noga, Basis-set convergence of correlated calculations on water, J. Chem. Phys., 106 (1997), pp. 9639-9646. DOI:

https://doi.org/10.1063/1.473863

56A.Halkier, T. Helgaker, P. Jørgensen, W. Klopper, J. Olsen, Basis-set convergence of the energy in molecular Hartree-Fock calculations, Chem. Phys. Lett. 302 (1999), pp. 437-446. DOI: https://doi.org/10.1016/S00092614(99)00179-7

$57 \mathrm{~F}$. Weigend, Efficient use of the correlation consistent basis sets in resolution of the identity MP2 calculations, J. Chem. Phys., 116 (2002), pp. 3175, DOI: https://doi.org/10.1063/1.1445115 
58G.L. Stoychev, A.A. Auer, F. Neese, Automatic Generation of Auxiliary Basis Sets, J. Chem. Theory Comput., 13 (2017), pp. 554-562. DOI:

https://doi.org/10.1021/acs.jctc.6b01041

${ }_{59}$ D.Q. Wu, G.U Xu, S.S. Qu, R.S. Xue, C.G. Gu, F. Zhang, Standard enthalpies of combustion and formation of porphyrin derivatives, Thermochim. Acta, 154 (1989), pp. 233-245. DOI: https://doi.org/10.1016/0040-6031(89)85460-7 ${ }_{60}$ R. Patino, L.A. Torres, M. Campos, The standard molar enthalpies of formation of 5,10,15,20-tetraphenylporphine and 5,10,15,20-tetrakis(4methoxyphenyl)porphine by oxygen bomb combustion calorimetry, J. Chem. Thermodyn., 31 (1999), pp. 627-634. DOI: https://doi.org/10.1006/jcht.1998.0469 ${ }_{61}$ D.R. Zakirov, D.V. Solomin, A.V. Volkov, A.S. Semeikin, M.I. Bazanov, Standard Entalpies of Combustion and Formation of Tetraphenylporphin, Russ. J. Phys. Chem., 73 (1999), pp. 2058-2059 [in Russian] 